\title{
Private car and public transportation: dynamics of the modal share
}

\author{
A. Bajracharya \\ The British University in Dubai, Dubai, UAE
}

\begin{abstract}
A large proportion of private car modal share and the increasing trend of car use are the main challenges in realising a sustainable urban transportation system. A set of feedback loop models has been developed in this paper to make an attempt to present such challenges. The dynamics of the modal share between the private car and public transportation (PT) have been explained in terms of the model. The model mainly indicates that if the PT travel time is longer, PT availability is sparse, PT station accessibility is difficult, and if PT use does not indicate the social "class" then there will be a strong need to own a private car and it would consequently develop a need-based desire for a car. In such a situation, if the large mass of the population can afford and easily buy a car, then car use would get persistently high. An important issue for transportation policy design would then be how to pull the large mass of an increasing car-dependent population to encourage using the PT.

Keywords: private car ownership and use, public transportation choice and use, dynamics of modal share, sustainable transportation, qualitative systems thinking.
\end{abstract}

\section{Introduction}

Study of the modal share dynamics in urban transportation is important in gaining insight into sustainable transportation system. Majority of the studies in the area of modal share generally use the common methods of mode choice such as binary and multinomial logit models [1]. The static methods based on crosssectional data might lead to unreliable analysis results, and thus Goodwin [2] argued that panel data could be used for better result and understanding. Ryuichi Kitamura undertook an extensive amount of research in this area, and in his 
latest work in Kitamura [3] he used a set of panel data to the study the dynamics of modal choice at household level. The forecasting based panel data analysis tool however could not accommodate many variables and the dynamic simulation was based on the replication of past behaviour of limited number of variables. Pfaffenbichler et al. [4] on the other hand presented a system dynamics approach in complex MARS model where the modal share in car has been presented in a broader context.

In this paper, emphasis is however given to a closer focus at an individual level modal choice dynamics in the context of an urban area. A systems thinking approach (see Sterman [5] for details) has been used to develop a feedback loop model to reflect the dynamics. General understanding is that a state of modal share in an urban area can be taken as a reflection of ridership behaviour of large mass of residing population. The ridership behaviour further can be taken as a reflection of collective modal use behaviour of individuals in the populace. The model assumes that there are only two modes of transportation - namely private car and public bus/train - are available in a city. The bi-modal assumption is valid in the context of city where other modes such as walking and cycling are usually not preferred. First the feedback loops pertaining to private car ownership and use are explained. Then another set of feedback loops pertaining to public transportation choice and use are presented. Lastly, by combining the two sets of feedback loops the collective dynamics of the use of private car and public transportation are discussed.

\section{Private car ownership and use}

Private car would be a part of daily life for those who can afford. If car ownership is taken as a material possession, the use of it could range from basic instrumental use to the purpose of acquiring affective and symbolic functions [6, 7]. The instrumental argument suggests that private car is simply a safe, comfortable and superior means of transportation - that is why people own and use private car. The symbolic argument explains that possession and use of private car exhibit one's social identity and status, and people desire to project one's status image in the society they live. The affective argument on the other hand highlights the fact that possession and use of private car would be closely related to one's emotional attachment and the attachment with pleasant feelings reinforce the desire to possess and use private car. The three motives however do not operate separately; they are rather related to each other [8]. This research starts with the line of thinking that probably the key construct that would basically reflect the urge that drives an individual to possess a private car would be the very desire to own and use car (Figure 1). If there is a real need of private car for personal and family use then one would seek and desire to own a car if it is affordable. At the same time the desire could be influenced by the availability of cars to choose from the market - that means more the car options are easily available in the market in terms of various designs and models more the desire would be there to own and use car. Another important parameter that influences the desire is the social need - possession of a car is also taken as a status symbol 


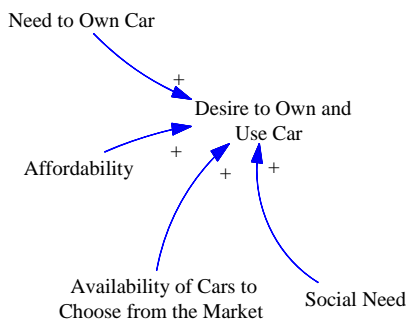

Figure 1: $\quad$ Desire to own and use a private car.

in society and the desire due to social need would be more pronounced in a caroriented society.

So the desire to own and use car would be affected by the basic transportation need, affordability, car availability in the market to choose from, and the social need. And once the desire is translated into real car ownership, it triggers some interesting dynamics of car use. First part of this dynamics has been identified in terms of a reinforcing feedback loop R1 (Figure 2) that can explain the perpetual use of private car. It is natural that the use of car would increase when one owns a car. Private car driving provides a level of satisfaction because of the instrumental, symbolic and/or affective satisfaction with the ownership and use of private car. This would enhance the desire to keep owning and using private car which will perpetually increase the use of the car, the satisfaction experience and it in turn nurtures the desire itself. The level of satisfaction would not only enhance the desire to own and use the car but it would also internally urge the user to simply drive more and it would further increase the use of car. This amplifier effect as noted by Stardling et al. [9] has been shown in another reinforcing feedback loop R2 (Figure 2). At the same time, the driving satisfaction would also be affected by the quality of car and road infrastructure. Better the quality more the satisfaction would be there.

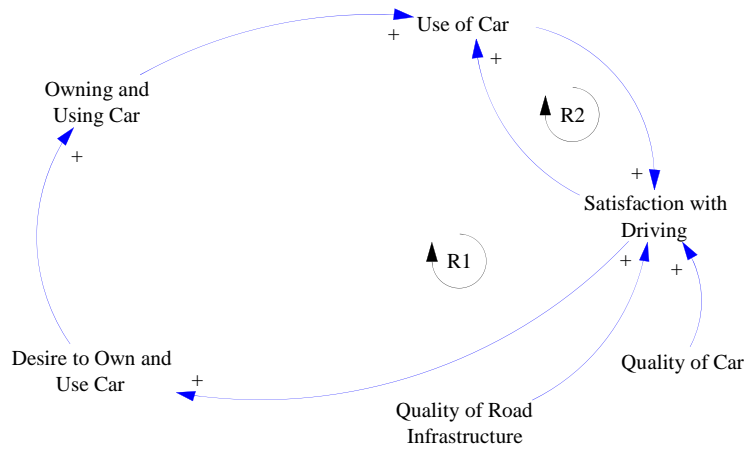

Figure 2: $\quad$ Reinforcing the use of the private car. 
Another facet of car use would be the probable discomfort and dissatisfaction associated with car driving. The dissatisfaction with driving would be exacerbated by the distance-wise travel time and traffic congestion. If one has to drive long distance on daily routine basis, then it would definitely not be pleasant. Likewise the routine of getting trapped into long grinding time in the traffic jam would be one of the very unpleasant experiences. All these discomfort and dissatisfaction in car driving would directly discourage the car use as shown in balancing feedback loop B1 (Figure 3), and continuous experience of such discomfort and dissatisfaction would even discourage one to own and use car as shown in balancing feedback loop B2 (Figure 3).

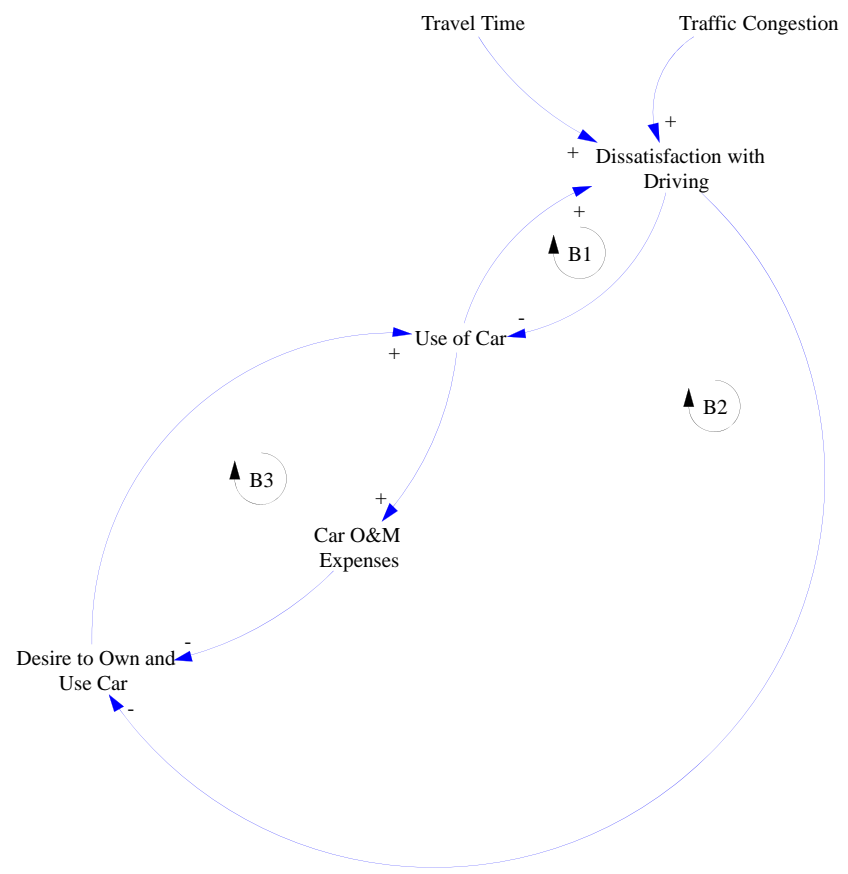

Figure 3: $\quad$ Limiting the use of the private car

Another issue that would discourage one to own and use car is the operations and maintenance (O\&M) expenses of car. Balancing feedback loop B3 (Figure 3) presents this issue, and the negative feedback loop effect would be more pronounced when there are substantial car ownership hurdles in terms of car registration and renewal processes, car and road use taxes, fuel price/surcharge, traffic fines, required insurances, and other repair and maintenance expenses.

\section{Public transportation choice and use}

The two sets of reinforcing feedback loops (R2 and R3) would explain the phenomenon of perpetual increase in the use of private car whereas the three sets 
of balancing feedback loops (B1, B2 and B3) indicate the possible situations that limit the car ownership and use. If an individual gets discouraged to own and use private car, then the alternative mode for transportation would be public transportation (PT) provided that it is available. The understanding here is that the use of PT and private car are mutually exclusive at individual trip level. The number of trips made in PT excludes a person to use potentially available private car for the same trips or vice versa. This understanding is presented in the reinforcing feedback loop R3 (Figure 4). The loop is interestingly a reinforcing loop in the sense that the continuous preference in one mode reinforces the use of the same mode excluding the other mode. This loop would also help to explain the habitual behaviour with preferred, available and routinely used mode of transportation.

Similarly as the private car, the use of PT would provide different experiences of riding satisfaction and dissatisfaction. And it is natural that more riding satisfaction would encourage the use of PT and it is possible that it further provides instances of satisfactory rides. This reinforcing loop R4 (Figure 5) would thus explain the probable persistent use of PT ridership. On the other hand

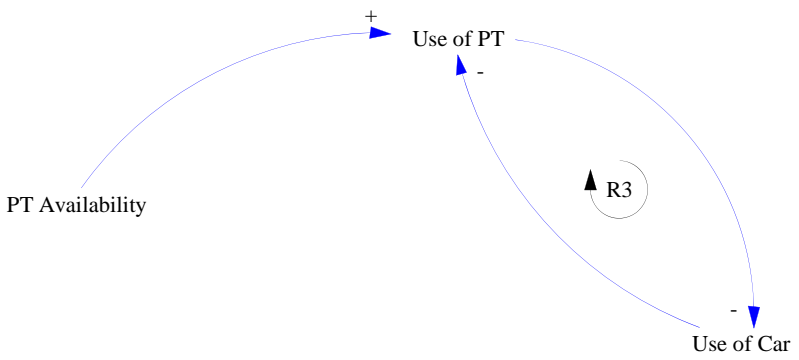

Figure 4: $\quad$ Mutually exclusive uses.

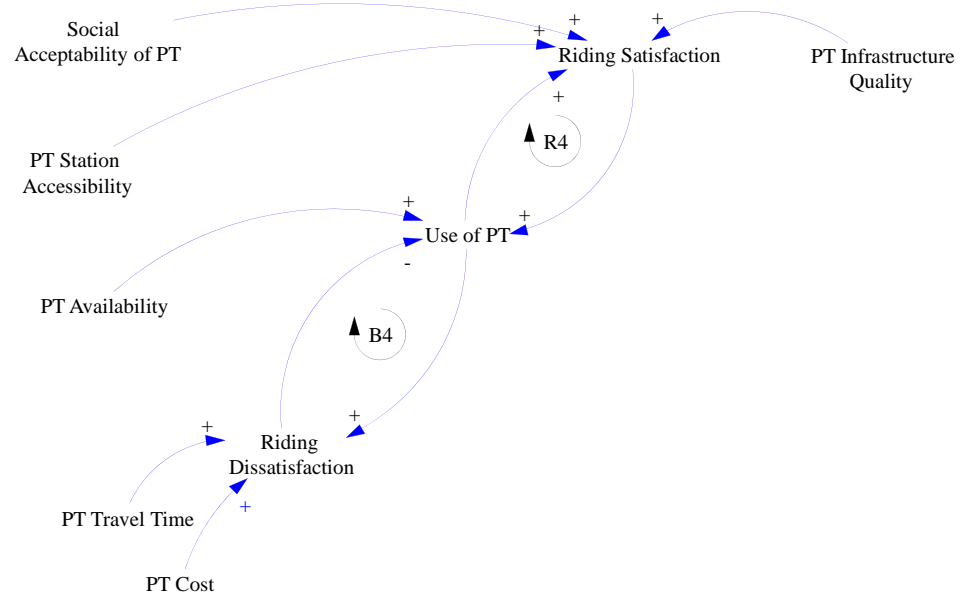

Figure 5: The use of public transportation. 
the instances of a dissatisfactory ride would limit the use of PT as depicted by the balancing loop B4 (Figure 5). Further, the satisfaction of PT use would be enhanced if the PT stations are accessible, the PT infrastructure quality is good, and importantly PT is socially acceptable. The dissatisfaction with PT on the other hand would be exacerbated if it takes longer trip time, for instance it takes long time to reach the PT station, to wait at the station, to make the real travel, to change carriers if needed, and to reach the final destination from the last station. The dissatisfaction would also be increased if the cost (especially the fare) of using PT is significantly high.

\section{The dynamics of the use of the private car and public transportation}

Combined dynamics of the use of private car and public transportation can be visualised if all the feedback loops discussed so far are assembled as shown in Figure 6. First, it is clear that the use of private car and PT is mutually exclusive at individual trip level. The car ownership and use behaviour could be selfreinforcing. If car is needed for personal use, preferred cars are affordable and they are available, the society is a car-oriented society, and road and car quality

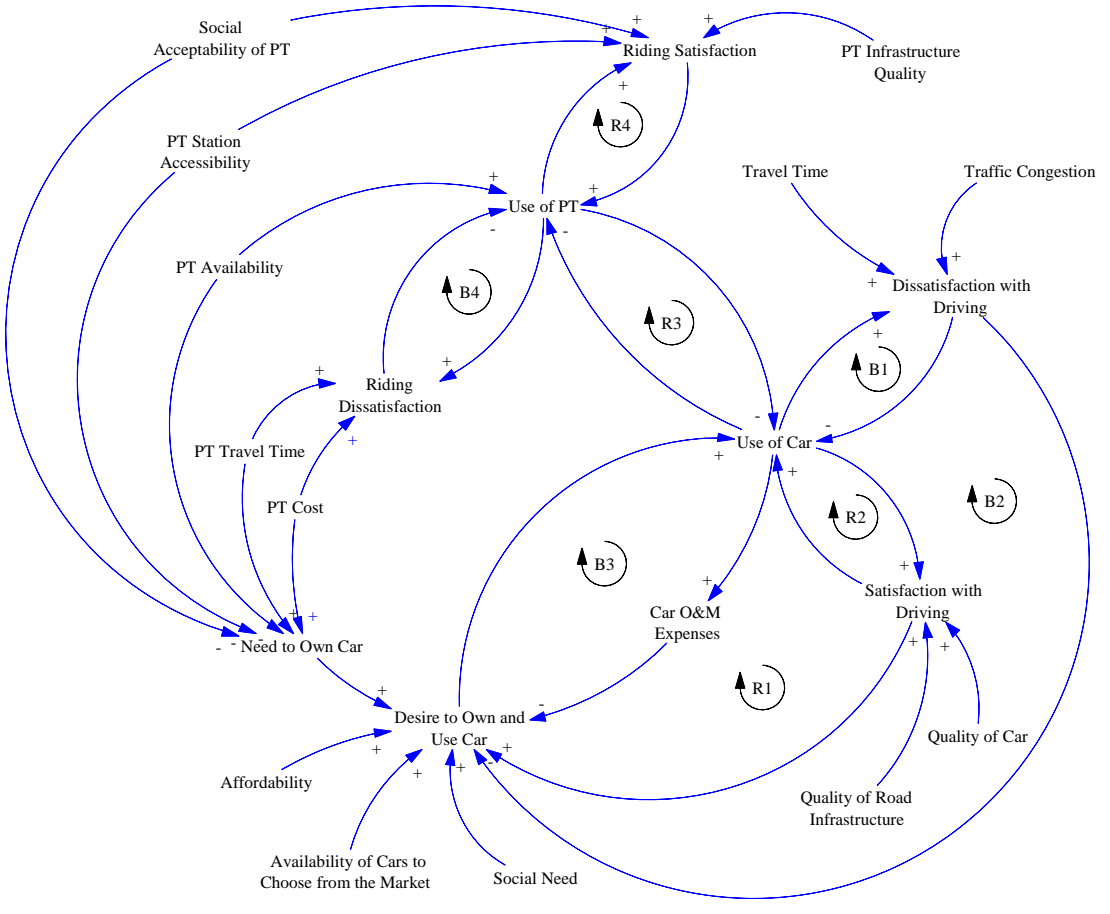

Figure 6: The dynamics of the use of the private car and public transportation. 
are good, then the car use could be perpetual and even habitual. At the same time using a car could be unpleasant in the condition of the need of frequent long tiring driving, traffic congestion, and accidents. Owning a car could also be frustrating if the car owning costs are high. Alternative of car use would be the use of PT if it is available. Experience of riding satisfaction in PT would encourage one to use it. The satisfaction level would be enhanced if the PT infrastructure quality is good, the PT stations are accessible, and the PT ridership is socially acceptable. Experience of riding dissatisfaction in PT on the other hand would discourage one to use it. Long bounded travel time and high costs would particularly be discouraging to use PT.

The combined feedback loops also indicate that if the PT travel time is longer, PT availability is sparse, PT station accessibility is difficult, and if the PT use does not indicate the social "class" then there will be a strong need to own private car and it would consequently develop a need-based desire of car. In such situation if the large mass of population can afford and easily buy car, then the car ridership would get persistently high. Important issue for transportation policy design would then be how to pull the large mass of increasing cardependent population to encourage using the PT.

\section{Conclusions}

A set of feedback loop model has been developed that can portray the dynamics of modal share between private car and PT. The systems thinking approach helped to assimilate a large number of relevant constructs that can collectively explain the individual mode choice behaviour. The model is a part of a research project in which the scope is to develop a full-fledged system dynamics simulation model to address a large proportion of persistent private car modal share and highly increasing trend of car ridership in a fast growing city. The next step in this research is to operationalise the conceptual feedback loop model by translating it into a detailed and structured computer simulation model.

\section{References}

[1] Mintesnot, G., \& Takano. S., Diagnostic Evaluation of Public Transportation Mode Choice in Addis Ababa. Journal of Public Transportation, 10(4), pp. 27-50, 2007.

[2] Goodwin, P. B., A Panel Analysis of Changes in Car Ownership and Bus Use. Traffic Engineering and Control, 27, pp. 519-525, 1986.

[3] Kitamura, R., A Dynamic Model System of Household Car Ownership, Trip Generation, and Modal Split: Model Development and Simulation Experiment. Transportation, 36, pp. 711-732, 2009.

[4] Pfaffenbichler, P., Emberger, G., \& Shepherd, S., A System Dynamics Approach to Land Use Transport Interaction Modelling: The Strategic Model MARS and its Application. System Dynamics Review, 26(3), pp. 262-282, 2010. 
[5] Sterman, J. D., Business Dynamics: Systems Thinking and Modelling for a Complex World, Irwin McGraw-Hill, New York, 2000.

[6] Dittmar, H., The Social Psychology of Material Possessions: To Have is To Be. Hemel Hempstead, UK: Harvester Wheatsheaf, 1992.

[7] Steg, L., Car Use: Lust and Must. Instrumental, Symbolic and Affective Motives for Car Use. Transportation Research, 39(2), pp. 147-162, 2005.

[8] Gatersleben, B., Affective and Symbolic Aspects of Car Use. In: Threats from Car Traffic to the Quality of Urban Life, ed. Gärling, T. \& Steg, L., Elsevier, The Netherlands, pp. 219-233, 2007.

[9] Stardling, S. G, Meadows, M. L., \& Beatty, S., Helping Drivers Out of their Cars: Integrating Transport Policy and Social Psychology for Sustainable Change. Transport Policy, 7, pp. 207-215, 2000. 